\title{
Availability of deep-water fish to trawling and visual observation from a remotely operated vehicle (ROV)
}

\author{
Verena M. Trenkel ${ }^{1, *}$, R. I. C. Chris Francis ${ }^{2}$, Pascal Lorance ${ }^{3}$, Stéphanie Mahévas ${ }^{1}$, \\ Marie-Joëlle Rochet ${ }^{1}{ }^{2}$ Dianne M. Tracey ${ }^{2}$
}

${ }^{1}$ Laboratoire MAERHA, IFREMER, Rue de l'Ile d'Yeu, BP 21105, 44311 Nantes Cedex 03, France

${ }^{2}$ National Institute of Water and Atmospheric Research Ltd, Private Bag 14901, Wellington, New Zealand

${ }^{3}$ Laboratoire Ressources Halieutiques, IFREMER, BP 70, 29280 Plouzané, France

\begin{abstract}
Visual observations were collected using video from a remotely operated vehicle (ROV) for a number of deep-water species on the continental slope of the Bay of Biscay, Northeast Atlantic. Relative trawl availability was defined as the ratio of population density estimates from a scientific bottom-trawl survey to those derived from visual strip transects. Several natural and reaction behaviour variables were explored to explain between-species variation in relative trawl availability. The variable with most explanatory power was spatial dispersion, with aggregating species showing lower relative availability than those that were randomly or uniformly distributed. This variable was also strongly correlated with ROV density estimates (aggregated species had the highest densities). Mean distance off the ground and mean body length of a species were positively related to relative trawl availability. In contrast, the way different species reacted to the ROV did not appear to be correlated with relative trawl availability.
\end{abstract}

KEY WORDS: Remotely operated vehicle $\cdot$ ROV $\cdot$ Catchability $\cdot$ Spatial distribution $\cdot$ Continental slope

Resale or republication not permitted without written consent of the publisher

\section{INTRODUCTION}

Scientific trawl surveys provide relative abundance indices for fish stock assessments. The constant of proportionality between these indices and the true population density is commonly referred to as the catchability coefficient. Catchability is known to have many components and can vary in response to factors such as species, population density, season, time of day and body size, which all interact with the fishing gear. For a given population, trawl catchability is commonly broken down into horizontal and vertical availability and gear efficiency (Godø 1994). Horizontal availability, which is the probability that an individual is found in the fishing area, is not studied in this paper. Vertical availability is the probability that an individual is at the right distance from the bottom in order to be caught by the particular fishing gear. Gear efficiency, defined as the probability that an individual that encounters the gear ends up in the catch, is determined by mesh size and reactions to the approaching gear. Most of the information on the different components of catchability comes from field studies of a few continental shelf species, in particular cod, haddock and some flatfish (Parrish et al. 1962, Hemmings 1973, Walsh 1991, Wardle 1993, Engås 1994, Godø 1994, Bublitz 1996). Laboratory studies have contributed to our understanding of fish reaction to gear, with respect to swimming ability (Harden Jones 1963, He 1993), hearing spectra (Chapman 1973, Hawkins 1973) and vision (Muntz 1983).

Little is currently known about the catchability of deep-sea species. The main insights come from comparative trawl studies, which indicate large differences in the relative catchabilities of different deep-sea spe- 
cies, depending on the kind of trawl and rigging used (Gordon \& Duncan 1985, Merrett et al. 1991, Gordon \& Bergstad 1992). An increase in towing speed and larger net openings seem to favour catches of large, fast swimming species such as Alepocephalus bairdii and Aphanopus carbo (Gordon \& Duncan 1985). Single warp rigging of a semi-balloon trawl leads to increased catches of the small anguilliform species, Synaphobranchus kaupii, compared to the traditional paired warp rigging previously used (Gordon \& Bergstad 1992). These authors claim that this difference can be explained by the higher physical disturbance created by the single warp. Thus, the catchability coefficient strongly depends on the trawl design and mode of deployment.

Spatial distributions of deep-water species, such as the aggregating orange roughy Hoplostethus atlanticus, have been found to vary between years, likely having major impacts on trawl catchability (Clark 1996, Kirchner \& McAllister 2002). Clark (1996) found that the variance of orange roughy biomass in New Zealand waters increased when high-density aggregations seemed to have formed after a closure of the fishery. Francis et al. (2003) showed clear evidence of annual variability in catchability when analysing trawl survey data for many New Zealand species. Moreover, high clustering, i.e. strongly skewed spatial distributions, leads to large variances of estimated abundances (Fréon et al. 1993).

If a method existed that provided true population density estimates, then a simple comparison with the relative trawl abundance indices would allow estimation of catchability coefficients (Somerton et al. 1999). Krieger \& Sigler (1995) estimated rockfish catchability to be between 0.97 and 1.27, assuming submersible counts provided true population density estimates. However, the hypothesis that visual observations collected from remotely operated vehicles (ROVs) or submersibles might provide such unbiased estimates for all species has not been confirmed, at least for deepwater species (Trenkel et al. 2004). In particular, the restricted vertical observation field and far distance avoidance reactions are suspected to bias certain population density estimates. Thus, visual observations are also subject to 'catchability' and species-specific differences in availability are to be expected. Nevertheless, visual observations are useful as a relative measure to study catchability of bottom trawls at a given site and point in time. As ROVs do not actually catch fish, we will adopt the terminology of relative availability for the remainder of this paper. Thus, we define relative trawl availability as the ratio obtained when dividing population density estimates derived from bottom trawl data by density estimates based on visual strip transects.
In this paper, we investigate the factors that could explain overall between-species differences in relative trawl availability to a commercial deep-sea trawl and to visual observation using an ROV. The data were collected on the continental slope of the Bay of Biscay, Northeast Atlantic (see also Trenkel et al. in press). In order to assess the effect of vertical availability, as well as that of gear efficiency, 4 explanatory factors were considered for each species (or family in certain cases) (1) average individual distance off the ground, (2) average body size, (3) type of spatial distribution and (4) average reaction to the approaching ROV.

\section{MATERIALS AND METHODS}

Study sites. Three sites were surveyed during late August 2002 with the IFREMER ROV 'Victor 6000' in the Bay of Biscay. The ROV 'Victor 6000' is a deepdiving $\operatorname{ROV}(3.1 \times 1.8 \times 2.1 \mathrm{~m}, 4 \mathrm{t})$ equipped with 8 frontal flood lights (total $2700 \mathrm{~W}$ ). The sites visited were Meriadzek Terrace, St Nazaire Terrace and Belle Ile Canyon (Fig. 1). At each site, the survey depth ranged from 1100 to $1500 \mathrm{~m}$, with the ROV working up the slope and operating in an identical way in all 3 areas. ROV operations at each site were carried out continuously over an approximately $75 \mathrm{~h}$ period. In addition, scientific trawling was carried out on the 2 terraces shortly after the ROV passed.

ROV data collection. The ROV travelled at constant speed $\left(0.25 \mathrm{~m} \mathrm{~s}^{-1}\right)$ and altitude $(0.8 \mathrm{~m})$ along predefined transect lines; the forward facing video camera recorded ahead and transmitted the images, in real time, to the IFREMER RV 'L'Atalante'. The survey design consisted of perpendicular transect strips (nominal lengths: $300 \mathrm{~m}$ along depth gradients and $60 \mathrm{~m}$ across) arranged in 6 ( 7 at Meriadzek Terrace) segments of roughly equal length, with total lengths of 24 (Meriadzek Terrace), 20 (St Nazaire Terrace) and 20 km (Belle Ile Canyon). Further details on sampling design can be found in Trenkel et al. (2004). Strip transect width was calibrated to $5 \mathrm{~m}$, at a distance of $1.5 \mathrm{~m}$ ahead of the ROV, by keeping all survey parameters constant ( $0.8 \mathrm{~m}$ above ground, fixed camera settings). All fish observed within the strip transect were counted in real time.

Individuals were later identified from video replays, where possible to species level. A number of species were grouped at the family level, as visual identification to species level was judged unreliable (see Appendix 1). For example, nearly all Moridae were North Atlantic codling Lepidion eques, but some common mora Mora moro and slender codling Halargyreus johnsonii were also encountered, and it was often difficult to confirm which identification was correct. In this 


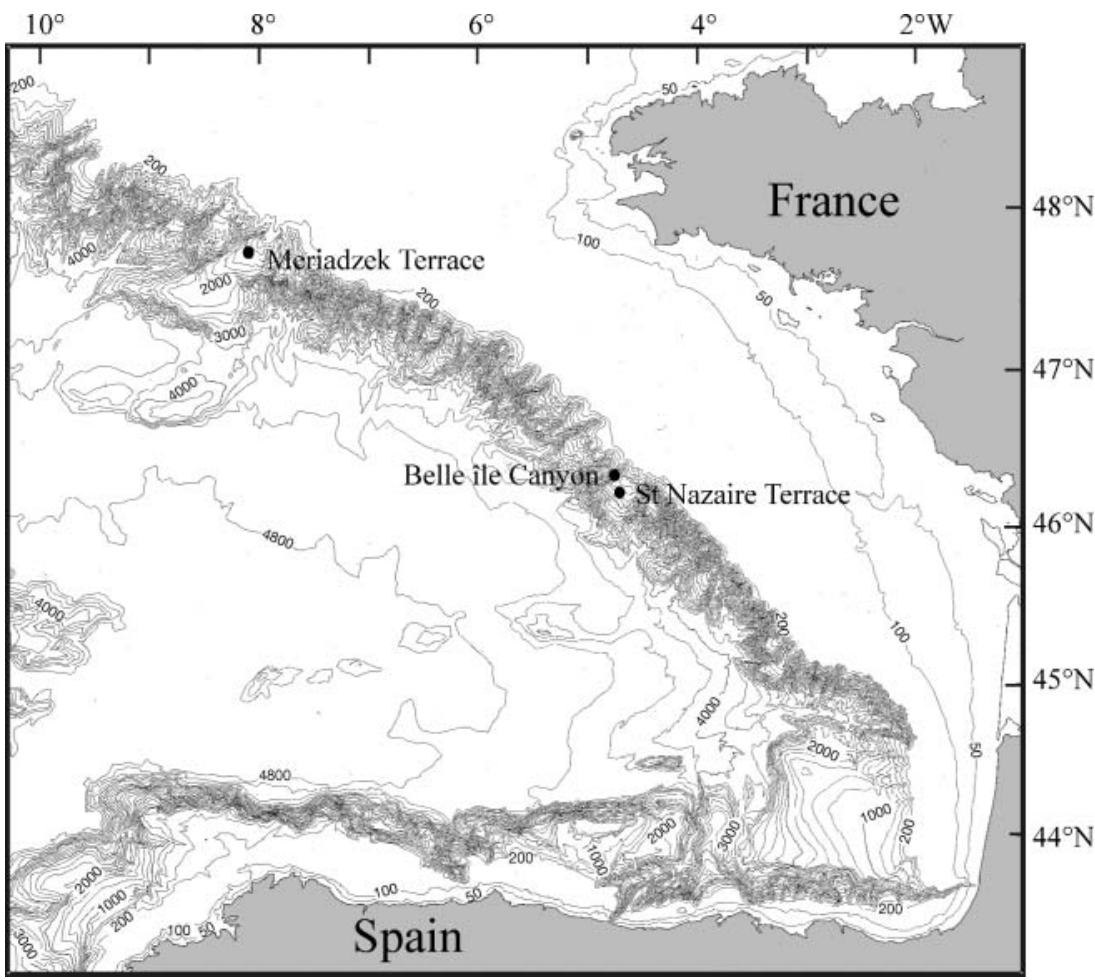

Fig. 1. Study areas: Meriadzek terrace, St Nazaire terrace and Belle Ile canyon. Isobaths are for 50,100, $200 \mathrm{~m}$ and then every $200 \mathrm{~m}$
Rochet, J. F. Cadiou, V. M. Trenkel unpubl. data). For roundnose grenadier Coryphaenoides rupestris, total length (TL) was converted to pre-anal length (PAL) using the relationship PAL $=0.2$ $\mathrm{TL}+1.68$ (P. Lorance unpubl. data).

Trawl data. Ten hauls with a standard commercial bottom trawl were carried out on the 2 terrace areas a few days after the ROV operation. Gear parameters for the net were: codend $60 \mathrm{~mm}$, door spread 82 to $145 \mathrm{~m}$, average headline height 4 to $5 \mathrm{~m}$ and wing spread around $20 \mathrm{~m}$. Tow duration was 45 to 60 min and towing speed 3 knots. The tows were carried out at $25 \mathrm{~m}$ depth intervals in each of the depth strata 1200 to $1300 \mathrm{~m}$ (e.g. 1200, 1225, 1250,1275 and $1300 \mathrm{~m}$ ) and 1400 to $1500 \mathrm{~m}$, following depth contours. All species in the catch were identified, counted and measured. For the roundnose grenadier, pre-anal length instead of total body length was measured.

Estimation of relative trawl availability. The visual strip transect method (Seber 1982) provided population density $(D)$ esti-mates as:

$$
D_{\mathrm{ROV}}=\sum_{i} N_{i} / \sum_{i} A_{i}
$$

where $N_{i}$ is the number of a given species encountered along transect leg $i$ and $A_{i}$ is the corresponding transect leg area. To estimate the uncertainty of density estimates, a non-parametric bootstrap (1000 resamples) of transect legs was carried out.

For the bottom-trawl data, swept area was estimated using horizontal net opening (taken as half the headline length due to lack of measurements) and trawled distance (trawl duration multiplied by trawl speed). Overall population density per study site was then estimated by summing all catches and dividing by the total swept area, ignoring depth stratification.

Relative trawl availability for species $r\left(q_{r}\right)$ was calculated as the ratio of the swept area-based density estimates to the ROV density estimates:

$$
\hat{q}_{r}=\hat{D}_{\text {trawl }} / \hat{D}_{\text {ROV }}
$$

with corresponding variance:

$$
\hat{V}\left(\hat{q}_{r}\right)=\hat{V}\left[\hat{D}_{\text {trawl }}\right] /\left(\hat{D}_{\text {ROV }}\right)^{2}+\left(\hat{D}_{\text {trawl }}\right)^{2} \hat{V}\left[\hat{D}_{\text {ROV }}\right] /\left(\hat{D}_{\text {ROV }}\right)^{4}
$$

following Kendall \& Stuart (1977), as the 2 density estimates were independent. Relative availability was calculated for each terrace separately. 
Creating explanatory variables. From the observations collected with the ROV, 4 explanatory variables based on observed natural and reaction behaviours were created. Due to the limited number of observations for certain species, data from all 3 study sites were combined. Hence, there was only 1 set of explanatory variables per species/family.

Distance off ground: The distribution of individual distances from the sea floor determines the average probability of a given species being observed by the ROV or caught by the trawl. The mean distance off the ground for each species was derived in the following way. The observation categories for distance off ground were translated into body lengths (bl) using the midpoints of each category, i.e. sitting $=$ touching $=$ $0 \mathrm{bl}, 1$ to 3 body lengths $=1.5 \mathrm{bl}$, $>3$ body lengths $=3 \mathrm{bl}$. An estimated distance off the ground was then calculated for each fish by multiplying this distance by the average body size of the species. Thereby, an average absolute measure of body position in the water column was obtained.

Body size: Smaller species are expected to have a lower probability of being retained by the trawl, while body size does not affect observability by the ROV. An index of species body size was derived from the average body size measured by the ROV (combining all study sites and depths). For slickheads (coded FMALEPO), rabbit fish (FMCHIMA) and false boarfish (NECYHEL), the average size was obtained from the catch data. As these species have rather large body sizes, average size based on catch data should provide a good estimate of average size in the population.

Reaction: Reactions to an approaching trawl can impact the probability of being retained by fishing gear. Although the reactions in front of the trawl were not directly observed, those observed with the ROV were used as proxies. Individuals showing no reaction were assigned a score of zero, while individuals that reacted but allowed the ROV to catch up with them got a score of +1 and those that escaped ahead of the ROV were marked -1 . This classification is based on the hypothesis that individuals that react, but allow the ROV to catch up with them, are most likely to be herded by the trawl sweeps and bridles and thus have an increased chance of being caught by a bottom trawl, hence the positive score. In contrast, individuals escaping from the ROV path would reduce their chances, which justifies the negative score. No reaction is considered neutral (score zero); these species are not herded, but will be caught if in the path of the net mouth. A reaction variable was created by calculating the average score for each species.

Many small species (spiderfish, false boarfish, morid cods and Kaup's arrowtooth eel) were assigned a value of zero for the reaction variable, as real time observa- tions showed that individuals did not essentially react to the ROV. However, no video replays with detailed characterisation of individual behaviours were carried out for these species.

Spatial distribution: The spatial distribution of a species will determine the distribution of numbers per transect line or numbers per haul and, as a consequence, the variability of abundance estimates. The baseline spatial distribution is a random distribution. Deviations from this can occur in 2 directions. At one end, individuals form clusters, and at the other, they show regular spatial patterns. Spatial distributions of ROV counts were analysed by fitting generalised linear models (McCullagh \& Nelder 1989) to total numbers per transect line. To account for systematic effects of environmental variables, such as study site, depth stratum, current speed category, relative survey direction with respect to current direction and day-night differences, a step-wise procedure was used to create the best fitting model for each species. Only second order interactions were included. The models were fitted using a quasi-likelihood method with variance proportional to the mean. If the spatial distribution was random, then the counts would follow a Poisson distribution and the variance would be equal to the mean. The estimated dispersion parameter of the fitted error distribution was used as an indicator for the spatial distribution. Spatial dispersion factor values around 1 indicate a random spatial distribution. Values greater than 1 imply that the species aggregates, while those less than 1 suggest individuals tend to avoid each other, resulting in a more uniform distribution. The spatial dispersion factors were ln-transformed before use as explanatory variables, so that values were of the same scale.

Modelling relative trawl availability. For analysis purposes, the estimated relative trawl availabilities for the 2 terraces were combined by taking the average. The relationship between relative trawl availability and each of the explanatory variables was explored using generalised additive models (GAMs) (Hastie \& Tibshirani 1990). Relative trawl availability was $\ln$-transformed to normalise variances. To deal with values of zero, a small value (0.001) was added before taking logarithms. All explanatory variables were modelled by smooth functions (cubic B-splines) with fixed degrees of freedom $(\mathrm{df}=3)$. Where the relationship appeared linear, linear models were also fitted. For this, the explanatory variables were centred in order to decorrelate intercept and slope estimates.

Trawl selectivity as a function of length is traditionally modelled by a sigmoid curve. Thus, the probability $\left(p_{i}\right)$ that a species of average length $l_{i}$ is retained by the gear is given by: 


$$
p_{i}=\frac{\exp \left(v_{1}+v_{2} l_{i}\right)}{1+\exp \left(v_{1}+v_{2} l_{i}\right)}
$$

If ROV availability is assumed to be independent of body size, then relative trawl availability might be approximated as $q_{r} \approx p$, ignoring any other factors. Hence, considering the ln-transformed relative trawl availability, the relationship with body size becomes:

$$
\ln \left(q_{r}\right) \approx v_{1}+v_{2} l_{i}-\ln \left[1+\exp \left(v_{1}+v_{2} l_{i}\right)\right]
$$

This function, referred to as the asymptotic model, was fitted to the data using non-linear least squares estimation.

The goodness-of-fit for each single factor model was evaluated using the Akaike information criterion (AIC) (Akaike 1974), calculated as:

$$
\mathrm{AIC}=n \ln (\mathrm{RSS} / n)+2 \mathrm{p}
$$

where $n$ is the number of observations, RSS the residual sums of squares and $\mathrm{p}$ the number of model parameters.

\section{RESULTS}

\section{Explanatory variables}

A number of species, in particular slickheads (FMALEPO) and dogfish sharks (FMSQUAL), were primarily seen higher up in the water column (Table 1). At the other end of the spectrum, the spiny scorpionfish (TRASCRI) and spiderfish (BATPDUB) were always sitting on the seabed. The small body size of a number of species makes efficient capture by the trawl with a codend mesh of $60 \mathrm{~mm}$ unlikely (Table 1). In particular, spiderfish and Kaup's arrowtooth eel (SYNAKAU) are very small bodied and rarely appeared in the catch, but were seen from the ROV. Observations from the visual transect showed that morid cods (FMMORID) were dominated by North Atlantic codlings Lepidion eques, a relatively small species, while in the catch, the slender codling Halargyreus johnsonii, which is of a similar size, was dominant. For the 2 species (spiderfish and North Atlantic codling) with sufficient size data collected

\begin{tabular}{|c|c|c|c|c|c|c|c|}
\hline \multirow[t]{2}{*}{ Species } & \multicolumn{3}{|c|}{ Mean distance off ground } & \multicolumn{2}{|c|}{$\begin{array}{c}\text { Mean body length } \\
\text { (ROV) }\end{array}$} & \multicolumn{2}{|c|}{$\begin{array}{l}\text { Mean body length } \\
\text { (Catch) }\end{array}$} \\
\hline & $\mathrm{N}$ & body lengths & $\mathrm{cm}$ & $\mathrm{N}$ & $\mathrm{cm}$ & $\mathrm{N}$ & $\mathrm{cm}$ \\
\hline FMALEPO & 17 & 1.8 & 90 & & & & \\
\hline Alepocephalus bairdii & & & & 2 & $46.7(5.7)$ & 856 & $65.6(13.1)$ \\
\hline BATPDUB & 794 & 0 & 0 & 103 & $20.3(3.6)$ & 25 & $21.1(4.8)$ \\
\hline FMCHIMA & 21 & 0.6 & 48 & & & & \\
\hline Chimaera monstrosa & & & & 6 & $97.3(10.6)$ & 93 & $80.9(16.7)$ \\
\hline Hydrolagus affinis & & & & 1 & 82.8 & 1 & 30 \\
\hline H. mirabilis & & & & 3 & $71.7(7.8)$ & 1 & 76 \\
\hline CORYRUP & 92 & 0.5 & 22.5 & 23 & $10.5(1.8)^{\mathrm{a}}$ & 1192 & $11.4(3.1)^{\mathrm{a}}$ \\
\hline HOPLATL & 23 & 0.6 & 21 & 6 & $33.0(3.5)$ & 307 & $44.5(10.4)$ \\
\hline NECYHEL & 22 & 0.7 & 18.48 & & & 5 & $26.4(1.5)$ \\
\hline FMMORID & 82 & 0.2 & 6 & & & & \\
\hline Halargyreus johnsonii & & & & & & 340 & $38.3(3.6)$ \\
\hline Lepidion eques & 82 & $0.2^{\mathrm{b}}$ & & 170 & $27.6(4.8)$ & 245 & $29.3(3.6)$ \\
\hline Mora moro & & & & 3 & $56.9(12.4)$ & 1 & 41 \\
\hline FMSCYLI & 18 & 1.1 & 36.3 & & & & \\
\hline Galeus melastomus & & & & 1 & 31.8 & & \\
\hline FMSQUAL & 20 & 1.1 & 110 & & & & \\
\hline $\begin{array}{l}\text { Centroscymnus } \\
\text { coelolepis }\end{array}$ & & & & & & 35 & $101.3(10.6)$ \\
\hline Deania calceus & & & & & & 495 & $88.2(7.6)$ \\
\hline SYNAKAU & 233 & $0.5^{\mathrm{c}}$ & 15 & 7 & $30.0(6.4)$ & & \\
\hline TRASCRI & 19 & 0 & 0 & 15 & $42.8(7.6)$ & 77 & $36.8(4.7)$ \\
\hline${ }^{a}$ Pre-anal length & & & & & & & \\
\hline${ }^{\mathrm{b}}$ From Uiblein et al. (2003) & & & & & & & \\
\hline${ }^{\mathrm{C}}$ From Uiblein et al. (2002) & & & & & & & \\
\hline
\end{tabular}

Table 1. Fish species coding, body distance off sea floor and mean body size (standard deviation) as estimated from the ROV parallel laser beam measurements and from the bottom trawl catches. See Appendix 1 for full list of species names 
from the ROV, mean size was calculated as being about $1 \mathrm{~cm}$ smaller in the in situ measurement than in the catch (Table 1).

In terms of reactions to the approaching ROV, $30 \%$ of roundnose grenadier (CORYRUP) and $9 \%$ of orange roughy (HOPLATL) started swimming ahead of the ROV but were finally caught up by it, while $9 \%$ and $4 \%$ respectively avoided the ROV, resulting in an average reaction variable of 0.22 and 0.05 , respectively (Table 2 ). This included a few orange roughy individuals observed descending rapidly from above the ROV and seeking refuge near the bottom. The lowest average reaction scores were obtained for dogfish sharks (FMSQUAL: -0.39) and slickheads (FMALEPO: -0.12).

The spatial distributions of a number of species showed systematic distribution patterns (spatial dispersion factor $<1$; Table 2 ). Only morid cods were more or less randomly distributed with a spatial dispersion factor close to 1. Two small species, spiderfish and Kaup's arrowtooth eel, exhibited clustering (spatial dispersion factor $>1$ ).

The exploration of relationships between explanatory variables revealed some strong patterns (Fig. 2).
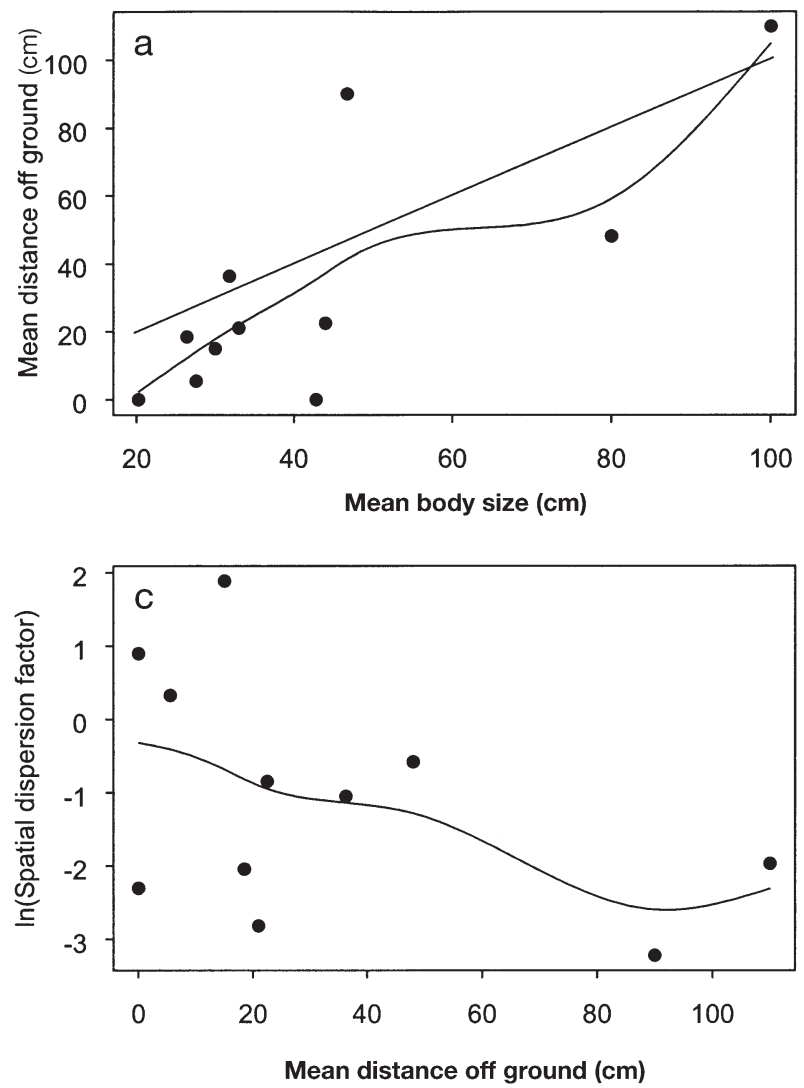

There seemed to be a tendency for larger species to be found further away from the sea-bottom (Fig. 2a). The spatial dispersion factor was negatively related to both body size and distance off ground (Fig. 2b,c). For exploratory purposes, the ln-transformed spatial dis-

Table 2. Reaction in front of the ROV and dispersion factor from a generalised linear model (GLM) (Poisson error with log-link) for the best fitting model for total numbers (N) per transect leg

\begin{tabular}{|lrcc|}
\hline Species & N & Reaction & $\begin{array}{c}\text { Spatial dispersion } \\
\text { factor }\end{array}$ \\
\hline FMALEPO & 17 & -0.12 & 0.04 \\
BATPDUB & 597 & 0 & 2.45 \\
CORYRUP & 90 & 0.22 & 0.56 \\
FMCHIMA & 55 & 0.14 & 0.43 \\
HOPLATL & 23 & 0.05 & 0.06 \\
FMMORID & 710 & 0 & 1.39 \\
NECYHEL & 44 & 0 & 0.13 \\
FMSCYLI & 74 & 0.15 & 0.35 \\
FMSQUAL & 41 & -0.39 & 0.14 \\
SYNAKAU & 3434 & 0 & 6.58 \\
TRASCRI & 19 & 0 & 0.1 \\
\hline
\end{tabular}
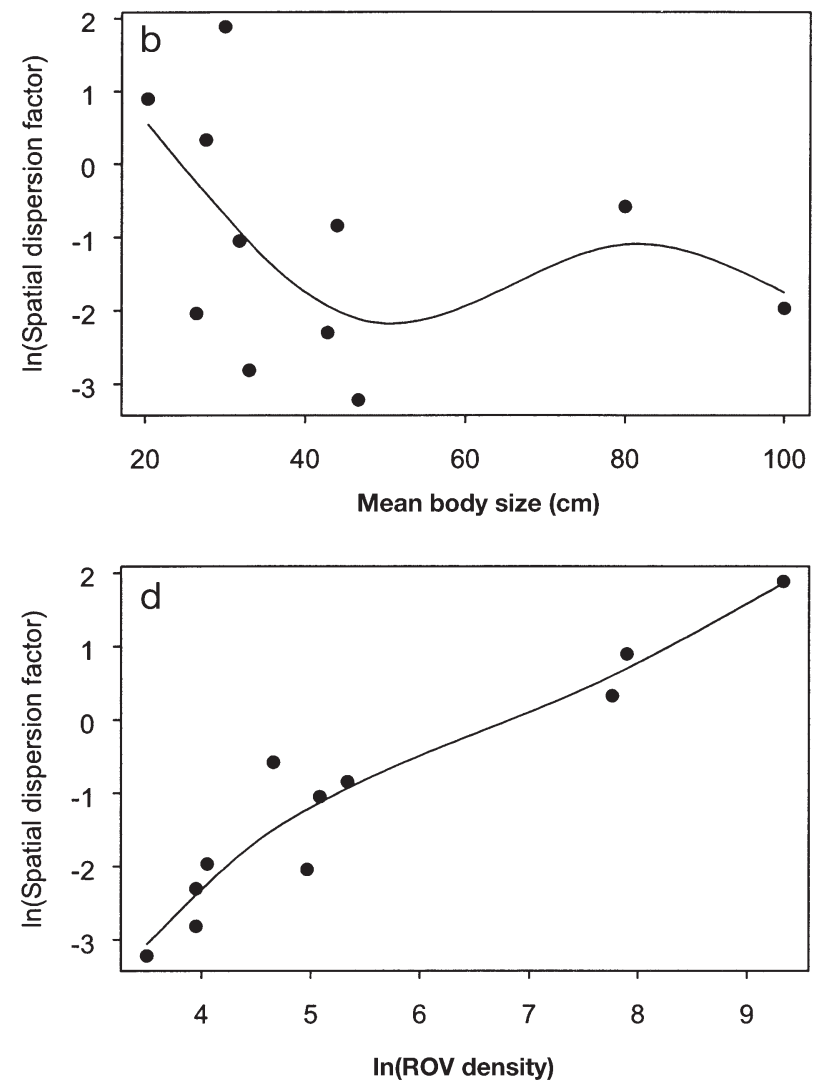

Fig. 2. Relationship between explanatory variables, (a) mean distance off ground versus mean body size; (b) spatial dispersion factor versus mean body size; (c) spatial dispersion factor versus mean distance off ground; (d) spatial dispersion factor versus ROV density. Non-parametic models were fitted using generalised additive models (GAMs) 
persion factor was also regressed against the ln-transformed average ROV density estimates (Fig. 2d). The observed correlation between the 2 factors was strong (correlation coefficient $=0.95$ ).

\section{Explanatory factors for relative trawl availability}

Relative trawl availabilities estimated for the 2 terrace sites were similar, and the largest values had the highest estimation uncertainty (Table 3). Kaup's arrowtooth eel (SYNAKAU) was never caught in the trawl, and hence, had a relative availability of zero and no estimate of standard deviation. Similarly, no false boarfish (NECYHEL) were caught on St Nazaire terrace, although a few individuals were caught on Meriadzek terrace.

The single factor model with the best fit overall was the linear model with $\ln$ (spatial dispersion factor) as explanatory variable (Table 4). This showed that aggregating species were relatively less available to the trawl. The asymptotic model of body size came second, while the linear model with distance off ground as covariable and the smooth model of reaction performed similarly to each other and somewhat worse than the first 2 models.

Table 3. Relative trawl availability $\left(q_{r}\right)$ for selected species with standard deviation (SD)

\begin{tabular}{|lcccc|}
\hline \multirow{2}{*}{ Species } & \multicolumn{2}{c}{ Meriadzek terrace } & \multicolumn{2}{c|}{ St Nazaire terrace } \\
& $q_{r}$ & SD & $q_{r}$ & SD \\
\hline FMALEPO & 113.15 & 85.08 & 21.67 & 12.81 \\
BATPDUB & 0.005 & 0.002 & 0.004 & 0.001 \\
FMCHIMA & 0.46 & 0.15 & 0.52 & 0.24 \\
CORYRUP & 5.50 & 2.44 & 5.79 & 2.62 \\
HOPLATL & 23.21 & 24.18 & 3.44 & 2.58 \\
FMMORID & 0.17 & 0.03 & 0.15 & 0.03 \\
NECYHEL & 0.04 & 0.03 & 0 & \\
FMSCYLI & 0.02 & 0.01 & 0.03 & 0.02 \\
FMSQUAL & 5.34 & 2.52 & 8.76 & 5.97 \\
SYNAKAU & 0 & & 0 & \\
TRASCRI & 1.16 & 0.68 & 0.839 & 0.51 \\
& & & & \\
\hline
\end{tabular}

Table 4. Goodness-of-fit for single factor models of relative trawl availability. RSS = residual sums of squares; $\mathrm{df}=$ degrees of freedom; AIC $=$ Akaike information criterion

\begin{tabular}{|lcccc|}
\hline Model factor & Model & df & RSS & AIC \\
\hline $\begin{array}{l}\text { ln(spatial dispersion } \\
\text { factor) }\end{array}$ & Linear & 9 & 48.10 & 19.08 \\
Body size & Asymptotic & 9 & 67.95 & 22.19 \\
Reaction & Smooth & 8 & 75.52 & 23.96 \\
Distance off ground & Linear & 9 & 85.74 & 24.29 \\
\hline
\end{tabular}

The mean distance off ground $\delta\left(\delta^{*}\right.$ when centred) was linearly related to ln-transformed relative trawl availability (Fig. 3a). The fitted relationship was $\ln \left(q_{r}\right)=-2.9-0.06 \partial^{*}$ (SD intercept $=1.29 ;$ SD slope $=$ $0.03 ; r^{2}=0.32$ ). Mean species body size was also linearly related to relative trawl availability, up to body sizes of around $30 \mathrm{~cm}$ (Fig. 3b). The fitted selectivity curve provided a good description of the data for species with smaller body lengths but not for species of intermediate size. The estimated parameters of the selectivity function were $v_{1}=2.69(4.78 \mathrm{SD})$ and $v_{2}=$ 0.39 (0.28 SD). No simple relationship was detected between the reaction variable and relative trawl availability (Fig. 3c). The spatial dispersion factor $\gamma$ (ln-transformed) showed a clear negative linear relationship (Fig. 3d). The fitted linear model for this was $\ln \left(q_{r}\right)=-1.06-1.74 \ln (\gamma)^{*}(\mathrm{SD}$ intercept $=0.70 ; \mathrm{SD}$ slope $\left.=0.46 ; r^{2}=0.62\right)$.

\section{DISCUSSION}

\section{Relative trawl availability}

In this study, we estimated 4 factors that might affect trawl availability for a number of deep-water species using visual observations obtained with an ROV: mean distance off ground, mean body size, spatial dispersion factor and reaction to the ROV. The first 3 factors showed strong relationships with relative trawl availability. These relationships can either be due to availability to ROV observation, availability to trawl catches or to both. The fact that relative trawl availability increased as a species was found further from the sea floor is most likely due to the difference in vertical coverage between the ROV $(\sim 2.5 \mathrm{~m})$ and the commercial trawl (4 to $5 \mathrm{~m})$. In contrast, the effect of body length will be due to trawl selectivity. The fitted model derived from the sigmoidal selectivity model provided a good description for smaller species but not for larger species, as, in addition to body size, other factors will impact relative trawl availability.

The different explanatory variables were independent of each other, with the exception of mean body size and mean distance off ground. Mean distance off ground was obtained by converting relative distance measured in body lengths into absolute distance by multiplying with mean body size. If all species had the same average distance off the ground in body lengths, the relationship would be exactly linear. However the results (Fig. 2a) show that the relationship is somewhat nonlinear. Hence, we believe that the variable distance off ground carries some independent information. 

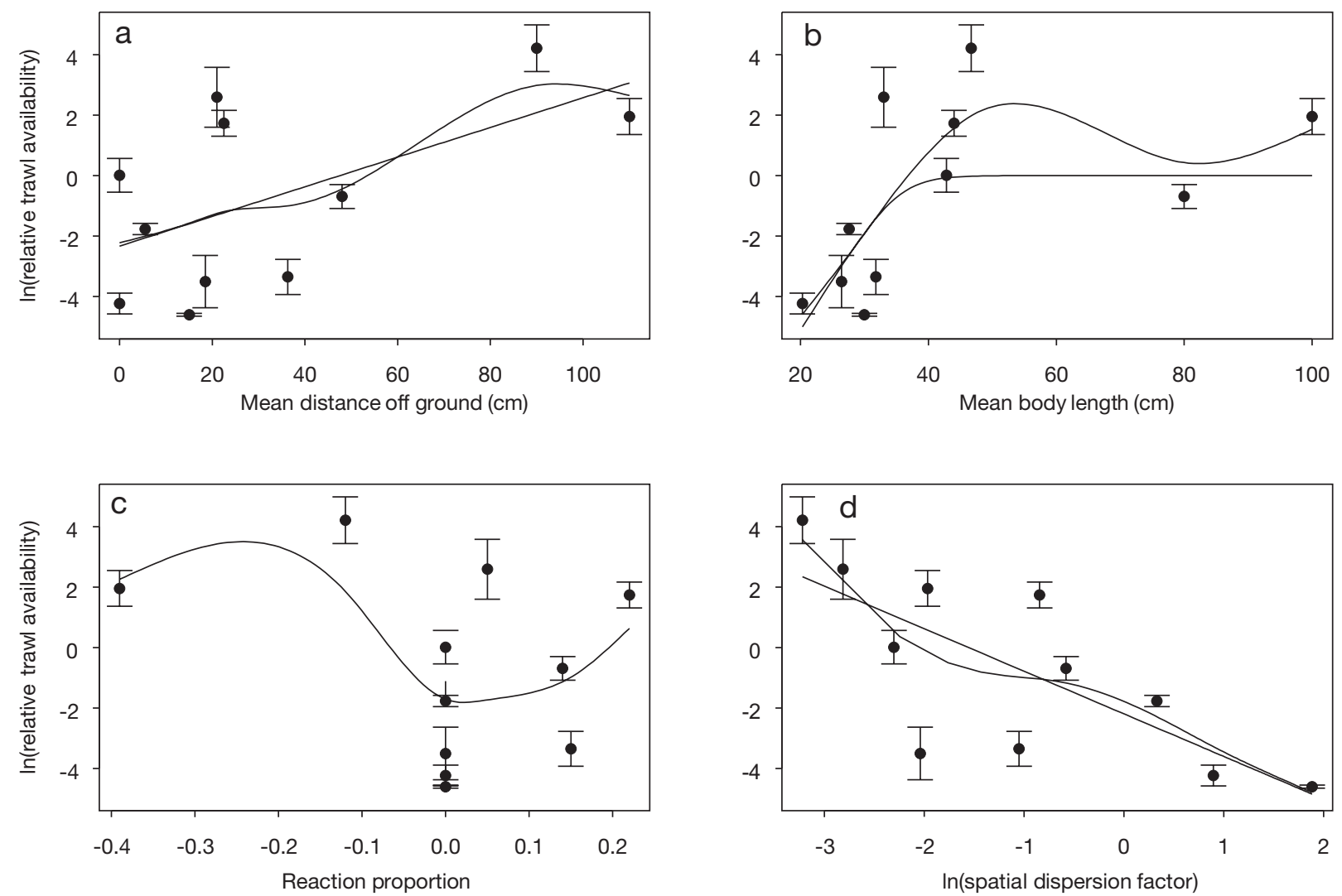

Fig. 3. Relationship between relative trawl availability (ln-scale) and explanatory variables: (a) mean distance off ground; (b) mean body length; (c) reaction; (d) spatial dispersion factor. Error bars indicate 1 SD. Non-parametric models fitted using GAMs

The best fitting single factor model was obtained when using the spatial dispersion factor as explanatory variable (ln-transformed). Conceptually, the spatial dispersion factor represents the relationship between the mean population density and its variance. As this factor was estimated using a Poisson model for which the variance is equal to the mean, the fact that the dispersion factor is a power function of the mean density $[\ln ($ dispersion factor $)=a+b \ln ($ density $)]$ indicates that the variance of the population density is a power function of its mean. This might, thus, lead to the interpretation that the relative trawl availability depends on the underlying population density, which in turn determines the spatial distribution. However, the underlying causal mechanism could also involve other nonexplored factors related to species biology. In this study, smaller species had lower relative trawl catchability. They also had higher ROV densities, which implies a higher spatial dispersion factor. These 2 relationships may have contributed to the strong negative correlation between relative trawl catchability and spatial dispersion factor. On the other hand, Tuck et al. (1997) also found a log-linear relationship when comparing the ratios of trawl population density estimates of Norway lobster Nephrops norvegicus to video survey-based estimates in areas with different burrow densities. In their case, the relationship cannot be due to species differences as only one species was involved.

Bottom trawl velocity was about 16 times that of the ROV surveying velocity. There is some evidence that the probability of reacting to the approaching ROV depends on surveying speed (P. Lorance \& V. M. Trenkel unpubl. data). Gordon \& Duncan (1985) noted that fast swimming species such as squalid sharks and Alepocephalidae have been caught in larger numbers by fast trawls with large vertical openings than by smaller, slower trawls. Hence, it cannot be excluded that, to some degree, the slow survey speed of the ROV led to an unrepresentatively low number of encounters for larger species. As a consequence, it seems important to investigate an explanatory variable which expresses swimming ability in future studies. Visual observations from a staffed submersible have been used to determine swimming speed relative to body size (Uiblein et al. 2002). Acoustic tags hidden in baits have also been employed to measure fish swimming speed (Armstrong et al. 1992). Further experiments combining these methods might allow assessment of both cruising and maximum velocity of different deepwater fish species. 
The findings of this paper apply to a set of deepwater species caught by the standard commercial trawl used in the area. Hence, it seems reasonable to assume that, although some variations in trawl rigging might occur within the deep-water fishery of the European Atlantic waters, these should have small effects on trawl availability and should not change the form of its relationship with different factors, as determined in this study.

\section{Suitability of ROV observations}

The number of available observations was rather limited for most species. Due to this, and also because of problems with identification, some species were analysed at the family level. Even after grouping into families, numbers of observations were low and so results have to be interpreted with caution. A drawback of analysing some species at family level is that, while related species share certain life history traits, they might differ in terms of spatial distributions, natural behaviour or reactions. This was clear for dogfish sharks (FMSQUAL), where birdbeak dogfish Deania calceus individuals were observed swimming fast and well off the bottom, far ahead of the ROV, while 1 kitefin shark Dalatias licha swam slowly close to the bottom and did not seem to avoid the ROV.

Data for the explanatory variables were also pooled over the 3 sites. There are some topographic, hydrological and fishing intensity differences between these sites (see Trenkel et al. 2004), but we do not believe that this had any effect on our analysis. The relative catchabilities were similar on both terraces and no clear difference was seen between sites in terms of the selected explanatory variables, apart from some differences in population densities.

In this study, reactions to the ROV were used as proxies for fish reactions occurring in front of the approaching trawl. The fact that no strong relationship was found between the reaction variable and relative trawl availability might be due to other factors being more important (e.g. local habitat conditions, time of day or depth) or indicate that reactions observed in front of the ROV were not representative. Although the ROV and the trawl are rather different observation platforms, they both will have provided auditory and, to some degree, visual stimuli for the fish. The noise emitted by the different engine parts of ROV 'Victor $6000^{\prime}$ has been measured to be particularly strong at low frequencies (20 to $800 \mathrm{~Hz}$, P. Arzelies pers. comm.). This corresponds to the range of sharpest hearing of many fish species (Hawkins 1973), although no measurements are currently available for deep-water fish. Unfortunately, no measurements are available for the noise emitted by the commercial trawl, so it is impossible to comment on the potential auditory stimulus. In addition to the noise, the floodlights of the ROV might have triggered reactions. It also seems likely that the moving trawl enhanced bioluminescence locally and, consequently, both the ROV and the trawl provided visual stimuli. However, the difference in the light spectrum of visual stimulus could be of some importance, as the vision of deep-water fish species has been found to be well adapted to the prevailing light frequencies in deeper waters (Muntz 1983). Two contrasting hypotheses can be formulated. Firstly, introducing artificial light might have blinded some species so that they did not show the same reaction towards the ROV as towards the trawl. Secondly, the lights could have triggered a reaction which was independent of light intensity or frequency and, hence, similar for the ROV and the trawl. In this study, roundnose grenadier and orange roughy were observed swimming ahead of the ROV. This behaviour can be explained by the optomotor reflex which leads to fish keep a fixed distance to a moving object, for example trawl wings or moving stripes in an experimental tank (Harden Jones 1963, Wardle 1993). The same behaviour should lead to herding by a trawl. Indeed, McClatchie et al. (2000) have reported herding of orange roughy by trawls.

\section{CONCLUSION}

Although the study was carried out for a selection of Bay of Biscay deep-water species at a particular time of the year using a particular trawl, the results should be of relevance for other situations. Firstly, the trawl used corresponded to the standard commercial deep-water trawl in operation in the Bay of Biscay. Secondly, the shape of the observed relationships between factors should apply in other cases. However, the results obtained in this study are based on observations of scattered deep-water fish, not on large aggregates as are known to appear in many areas for a certain number of deep-water species. Thus, the relationship between relative trawl availability and spatial dispersion factor or ROV population density might be expected to be different in these cases. Thirdly, the methodological approach used in this paper can be applied to any species, whether it is a deep-water or a shelf species. Thus, instead of primarily focusing on the comparison of visual density estimates obtained by ROVs, staffed submersibles or divers to catch-based density estimates in order to estimate catchability (Uzmann et al. 1977, Kulbicki \& Wantiez 1990, Krieger 1992, Krieger \& Sigler 1995), visual observations should also be used to provide insights into the importance of different behavioural and ecological factors. 
Acknowledgements. We are grateful to our colleagues, the pilots of 'Victor 6000' and the crews of RV 'L'Atalante' for assisting in the data collection during the cruise in the Bay of Biscay. We thank P. Arzelies (IFREMER/Toulon) for data on noise emitted by 'Victor 6000'.

\section{LITERATURE CITED}

Akaike A (1974) A new look at the statistical model identification. IEEE (Inst Electr Electron Eng) Trans Automatic Control AC 19:716-723

Armstrong JD, Bagley PM, Priede IG (1992) Photographic and acoustic tracking observations of the behaviour of the grenadier Coryphaenoides (Nematonurus) armatus, the eel Synobranchus bathybius, and other abyssal demersal fish in the North Atlantic Ocean. Mar Biol 112:535-544

Bublitz C (1996) Quantitative evaluation of flatfish behaviour during capture by trawl gear. Fish Res 25:293-304

Chapman CJ (1973) Field studies of hearing in teleost fish. Helgol Wiss Meeresunters 24:371-390

Clark MR (1996) Biomass estimation of orange roughy: a summary and evaluation of techniques for measuring stock size of a deep-water fish species in New Zealand. J Fish Biol 49(Suppl A):114-131

Engås A (1994) The effects of trawl performance and fish behaviour on the catching efficiency of demersal sampling trawls. In: Fernö A, Olsen S (eds) Marine fish behaviour in capture and abundance estimation. Fishing News Books, Oxford, p 45-68

Francis RICC, Hurst RJ, Renwick JA (2003) Quantifying annual variation in catchability for commercial and research fishing. Fish Bull 101:293-304.

Fréon P, Gerlotto F, Misund OA (1993) Consequences of fish behaviour for stock assessment. ICES J Mar Sci 196:190-195

Godø OR (1994) Natural fish behaviour and catchability of groundfish. ICES CM 1994/G14

Gordon JDM, Bergstad OA (1992) Species composition of demersal fish in the Rockall Trough, North-Eastern Atlantic, as determined by different trawls. J Mar Biol Assoc UK 72:213-230

Gordon JDM, Duncan J (1985) The ecology of the deep-sea benthic and benthopelagic fish on the slopes of the Rockall Trough, Northeastern Atlantic. Prog Oceanogr 15: 37-69

Harden Jones F (1963) The reaction of fish to moving backgrounds. J Exp Biol 40:437-446

Hastie TJ, Tibshirani RJ (1990) Generalized additive models, Monographs on statistics and applied probability 43. Chapman \& Hall, Boca Raton, FL

Hawkins A (1973) The sensitivity of fish to sounds. Oceanogr Mar Biol Annu Rev 11:291-340

He P (1993) Swimming speeds of marine fish in relation to fishing gears. ICES J Mar Sci 196:183-189

Hemmings CC (1973) Direct observation of the behaviour of fish in relation to fishing gear. Helgol Wiss Meeresunters 24:348-360

Kendall M, Stuart A (1977) The advanced theory of statistics, Vol 1. Charles Griffin, London
Kirchner C, McAllister M (2002) A new improved method to compute swept area estimates of biomass from commercial catch rate data: application to Namibian orange roughy (Hoplostethus atlanticus). Fish Res 56:69-88

Krieger KJ (1992) Distribution and abundance of rockfish determined from a submersible and by bottom trawling. Fish Bull 91:87-96

Krieger KJ, Sigler MF (1995) Catchability coefficient for rockfish estimated from trawl and submersible surveys. Fish Bull 94:282-288

Kulbicki M, Wantiez L (1990) Comparison between fish by catch from shrimp trawlnet and visual census in St. Vincent Bay, New Caledonia. Fish Bull 88:667-675

McClatchie S, Thorne R, Grimes P, Hanchet S (2000) Ground truth and target identification for fisheries acoustics. Fish Res 47:173-191

McCullagh P, Nelder JA (1989) Generalized linear models, Chapman \& Hall, London

Merrett NR, Gordon JDM, Stehmann M, Haedrich RL (1991) Deep demersal fish assemblage structure in the Porcupine seabight (Eastern North Atlantic): slope sampling by three different trawls compared. J Mar Biol Assoc UK 71: 329-358

Muntz W (1983) Bioluminescence and vision. In: MacDonald A, Priede IG (eds) Experimental biology at sea. Academic Press, London, p 217-238

Parrish BB, Blaxter JHS, Dickson W (1962) Photography of fish behaviour in relation to trawls. ICES CM 1962/77

Seber G (1982) The estimation of animal abundance and related parameters. Macmillan, New York

Somerton D, Ianelli J, Walsh S, Smith S, Godø OR, Ramm D (1999) Incorporating experimentally derived estimates of survey trawl efficiency into the stock assessment process: a discussion. ICES J Mar Sci 56:299-302

Trenkel VM, Lorance P, Mahévas S (2004) Do visual transects provide true population density estimates for deep-water fish? ICES J Mar Sci 62:1050-1056

Tuck ID, Chapman CJ, Atkinson RJA, Bailey N, Smith RSM (1997) A comparison of methods for stock assessment of the Norway lobster, Nephrops norvegicus, in the Firth of Clyde. Fish Res 32:89-100

Uiblein F, Lorance P, Latrouite D (2002) Variation in locomotion behaviour in northern cutthroat eel (Synaphobranchus kaupi) on the Bay of Biscay continental slope. DeepSea Res I 49:1689-1703

Uiblein F, Lorance P, Latrouite D (2003) Behaviour and habitat utilization of seven demersal fish species on the Bay of Biscay continental slope, NE Atlantic. Mar Ecol Prog Ser 257:223-232

Uzmann JR, Cooper RA, Theroux RB, Wigley RL (1977) Synoptic comparison of three sampling techniques for estimating abundance and distribution of selected megafauna: submersible vs camera sled vs otter trawl. Mar Fish Rev 39:11-19

Walsh SJ (1991) Diel variation in availability and vulnerability of fish to a survey trawl. J Appl Ichthyol 7:147-159

Wardle C (1993) Fish behaviour and fishing gear. In: Pitcher TJ (ed) Behaviour of teleost fishes. Chapman \& Hall, London, p 609-643 
Appendix 1. Names of deep-water species studied and identities of species being regrouped in the analysis

\begin{tabular}{|c|c|c|c|}
\hline Code & Species & Family & English name \\
\hline FMALEPO & $\begin{array}{l}\text { Alepocephalus bairdii } \\
\text { A. rostratus }\end{array}$ & Alepocephalidae & Slickheads \\
\hline BATPDUB & Bathypterois dubius & Ipnopidae & Spiderfish \\
\hline \multirow[t]{2}{*}{ FMCHIMA } & $\begin{array}{l}\text { Chimaera monstrosa } \\
\text { Hydrolagus affinis }\end{array}$ & & \\
\hline & H. mirabilis & Chimaeridae & Rabbit fish \\
\hline CORYRUP & Coryphaenoides rupestris & Macrouridae & Roundnose grenadier \\
\hline HOPLATL & Hoplostethus atlanticus & Trachichthyidae & Orange roughy \\
\hline NECYHEL & Neocyttus helgae & Oreosomatidae & False boarfish \\
\hline \multirow[t]{2}{*}{ FMMORID } & $\begin{array}{l}\text { Lepidion eques } \\
\text { Halargyreus johnsonii }\end{array}$ & & \\
\hline & Mora moro & Moridae & Morid cods \\
\hline \multirow{2}{*}{ FMSCYLI } & Apristurus sp. & & \\
\hline & Galeus melastomus & Scyliorhinidae & Cat sharks \\
\hline \multirow[t]{2}{*}{ FMSQUAL } & $\begin{array}{l}\text { Centroscymnus coelolepis } \\
\text { C. crepidater } \\
\text { C. squamosus } \\
\text { Deania calceus } \\
\text { Dalatias licha } \\
\text { Etmopterus princeps } \\
\text { E. spinax }\end{array}$ & & \\
\hline & Scymnodon ringens & Squalidae & Dogfish sharks \\
\hline SYNAKAU & Synaphobranchus kaupii & Synaphobranchidae & Kaup's arrowtooth eel \\
\hline TRASCRI & Trachyscorpia cristulata echinata & Scorpaenidae & Spiny scorpionfish \\
\hline
\end{tabular}

Editorial responsibility: Otto Kinne (Editor),

Oldendorf/Luhe, Germany
Submitted: February 12, 2004; Accepted: August 31, 2004 Proofs received from author(s): December 6, 2004 